\title{
THE IMPACTS OF LIFESTYLE BEHAVIOR ON Medicare Costs: A Panel Data Analysis at THE STATE LEVEL
}

\author{
Hyungjoon Jeon ${ }^{1}$, Sang H. Lee ${ }^{2}$ and David Wyld ${ }^{3}$ \\ ${ }^{1}$ Department of Tax Management, Changwon National University, Changwon City, \\ South Korea \\ ${ }^{2}$ Department of Management and Business Administration, Southeastern Louisiana \\ University, Hammond, USA \\ ${ }^{3}$ Department of Management and Business Administration, Southeastern Louisiana \\ University, Hammond, USA
}

\begin{abstract}
This article is a departure from many prior studies in the literature on Medicare spending in the United States. Previous works have focused on time-invariant or hereditary demographic characteristics and congenital health status. In contrast, this study examined state-level variations in Medicare costs per enrollee with special emphasis on prominent acquired health-related lifestyle attributes that are more reversible over a short time period. Our main findings are (1) reversible acquired health-related lifestyle attributes such as smoking and obesity are statistically significant determinants of state-level variations in Medicare costs; and (2) state-level variations in Medicare spending is elastic with respect to changes in the prevalence of the two acquired health-related lifestyle attributes.
\end{abstract}

\section{KEYWORDS}

Medicare, Fixed-effects Model, Random-effects Model

\section{INTRODUCTION}

Since its inception, Medicare has been a health safety net program for people 65 or older and younger people with certain disabilities. As of July 2013, "nearly 50 million Americans - 15 percent of the nation's population - depend[ed] on Medicare for their health insurance coverage" [1]. However, rapidly rising Medicare expenditure, together with increasing life expectancy at birth, has made Medicare partly perceived as a federal law which is "dependency-shifting rather than dependency-reducing: mandated dependence of the elderly on the federal government and taxpayers replaced potential dependence on family and charity" [2, p.310]. While the long-run budgetary situation for Medicare is a federal fiscal issue of great concern [3, 4, 5], state-level variations in Medicare costs per enrollee has been another issue of importance for policymakers, because of the interest in determining whether Medicare is federal program [6].

In the literature on Medicare expenditures, multi-faceted efforts have been made to examine state level variations in Medicare spending per enrollee. Along the demand-side margin for instance, several studies focused on geographical variations in Medicare spending and attempted to link such disparities to observable demographic characteristics, socioeconomic factors, and the

DOI: $10.5121 /$ hiij.2014.3301 
general health status of population across different states $[6,7,8,9,10,11,12]$. Those observable explanatory factors include, but not limited to, age, sex, race, education, income, and selfreported health status.

On the other hand, some studies took a supply-side approach to explaining state level variations in Medicare spending [6,11, 13, 14, 15]. These studies controlled for the supply of certain medical resources or health care market characteristics in a region such as level of managed care penetration and the number of physicians as a share of older population.

Building upon the existing literature of Medicare spending, this study examines state level variations in Medicare costs per enrollee using a "large N, small T" panel. The data consists of observations from 50 states and the District of Columbia ( $=51)$ over the 2003-2010 period $(\mathrm{T}=8)$. This study departs from the existing literature in several ways, which we will detail forthwith.

First, we place special emphasis on measurable health-related lifestyle attributes at the state level. Instead of controlling for a more complete set of explanatory variables, which potentially results in a multicollinearity problem and biased estimation outcomes, we confine explanatory variables only to the most often-used measure of the standard of living (Gross Domestic Product per capita) and two of the most prominent health-related lifestyle attributes (prevalence of smoking and level of obesity in the adult population). The main reasoning behind this approach is straightforward. Unlike time-invariant or hereditary characteristics, such as sex, race, education, and chronic health issues, some of the acquired health-related habits are more reversible over a relative short time period. If state level prevalence of such reversible health-related lifestyle attributes is highly statistically correlated with state level variations in Medicare costs, this paper will provide important public health policy implications and strategies for promoting healthier lifestyles.

Second, we presume that state level variations in Medicare spending are also attributed to many unobserved state-specific or Medicare beneficiary-specific factors. To test this assumption, we examine regional disparities in Medicare costs per enrollee by fitting panel data regression models. Then, we attempt to identify an efficient panel estimator by testing whether or not such health-related lifestyle characteristics are correlated with some unobserved state- or Medicare beneficiary-specific factors. In addition, this study incorporates nonlinearities into its linear empirical specification by using a log-log model. This is being done so that regression results are translated into more lucid policy implications.

The rest of the study is organized as follows. Section 2 discusses explanatory variables and provides a brief overview of the sample observations at state level. In Section 3, we introduce two panel data regression models and contrasts the assumptions underlying the two regression models. Section 4 analyzes the empirical results, and the policy implications of the findings follow in Section 5.

\section{DATA}

To explain the variations in Medicare costs per enrollee at state level, this study gathers statelevel information on the standard of living and lifestyle attributes for the 50 states and the District of Columbia over a time period of eight years (2003-2010). The overall descriptive statistics are summarized in Table 1. Medicare costs per enrollee at state level (denoted by medicost hereafter), prevalence of obesity among adults (age 18 and older) at state level (obesity), and prevalence of 
smoking in the adult population (age 18 and older) at state level (smoking) have been collected from the Robert Wood Johnson Foundation (RWJF) Data Hub.

Table 1. Descriptive statistics for the sample observations

\begin{tabular}{|l|l|l|l|l|l|}
\hline Variable & Mean & Std. Dev. $^{*}$ & Min $^{*}$ & Max $^{*}$ & Obs. \\
\hline medicost $^{\dagger}$ & $\$ 6660.9$ & $\$ 408.87$ & $\$ 5,684.1$ & $\$ 7,500.6$ & 408 \\
\hline gdppc $^{\dagger}$ & $\$ 43,049.6$ & $\$ 1,518.2$ & $\$ 33,822.4$ & $\$ 49,040.6$ & 408 \\
\hline smoking & 20.096 & 1.5230 & 17.0123 & 23.4703 & 406 \\
\hline obesity & 25.397 & 1.8890 & 21.453 & 29.0573 & 406 \\
\hline
\end{tabular}

${ }^{\dagger}$ medicost and gdppc are measured in 2000 dollars.

"The reported standard deviations, minimums and maximums are all within numbers.

Source: Robert Wood Johnson Foundation (RWJF) Data Hub (http://www.rwjf.org/en/researchpublications/research-features/rwjf-datahub.html) and_Bureau of Economic Analysis (http://www.bea.gov/itable/index.cfm)

First, the source of the data on Medicare costs per enrollee at state level is the Dartmouth Atlas Project (http://www.dartmouthatlas.org/tools/) which has documented variations in the average amount of Medicare spending per enrollee in each state for more than 20 years. This study uses the annual observations of real Medicare costs per enrollee (in constant 2000 dollars) at the state level from the 2003-2010 time period. Table 2 reports the top 5 states in Medicare costs per enrollee in 2003, 2005, and 2010, respectively.

Table 2. Top 5 states in Medicare costs per enrollee in 2000 dollars

\begin{tabular}{|l|l|l|}
\hline $\mathbf{2 0 0 3}$ & $\mathbf{2 0 0 5}$ & $\mathbf{2 0 1 0}$ \\
\hline $\begin{array}{l}\text { Louisiana } \\
(\$ 8,133.3)\end{array}$ & $\begin{array}{l}\text { Louisiana } \\
(\$ 8,663.0)\end{array}$ & $\begin{array}{l}\text { Louisiana } \\
(\$ 9,243.4)\end{array}$ \\
\hline Texas & Texas & Florida \\
$(\$ 7,138.4)$ & $(\$ 7,819.5)$ & $(\$ 8,789.5)$ \\
\hline Florida & Florida & Texas \\
$(\$ 7,131.7)$ & $(\$ 7,661.8)$ & $(\$ 8,782.4)$ \\
\hline Oklahoma & Oklahoma & Mississippi \\
$(\$ 7,088.5)$ & $(\$ 7,608.8)$ & $(\$ 8,465.6)$ \\
\hline $\begin{array}{l}\text { Alabama } \\
(\$ 7,027.3)\end{array}$ & Mississippi & Kentucky \\
$(\$ 7,556.9)$ & $(\$ 8,318.2)$ \\
\hline
\end{tabular}

Source: Robert Wood Johnson Foundation (RWJF) Data Hub (http://www.rwjf.org/en/researchpublications/research-features/rwjf-datahub.html)

The first measure of health-related lifestyles relates to obesity. The state level estimates of the prevalence of obesity among adults are based on 2-year averages of the Behavioral Risk Factor Surveillance Survey (BRFSS) data (http://www.cdc.gov/brfss/). Body Mass Index (BMI) is a number calculated from a person's weight and height. BMI provides a reliable indicator of body fatness for most people and is used to screen for weight categories that may lead to health problems. Following the standard weight status categories, the prevalence of obesity is defined as the percent of adults whose Body Mass Index (BMI) is over 30. Since the observations of obesity 
among adults at the state level are 2-year averages, this study first fits the 2-year averages of the prevalence of obesity over the 2003-2010 sample time period, and then uses its annual fitted values for statistical analysis and inferences. Table 3 reports the top 5 states in prevalence of obesity among adults in the 2003-2004, 2007-2008, and 2009-2010 time periods, respectively.

Table 3. Top 5 states in prevalence of obesity in adult population

\begin{tabular}{|l|l|l|}
\hline $\mathbf{2 0 0 3 - 2 0 0 4}$ & $\mathbf{2 0 0 7 - 2 0 0 8}$ & $\mathbf{2 0 0 9 - 2 0 1 0}$ \\
\hline Mississippi & Mississippi & Mississippi \\
$(28.81 \%)$ & $(32.98 \%)$ & $(34.94 \%)$ \\
\hline Alabama & Alabama & Louisiana \\
$(28.59 \%)$ & $(31.58 \%)$ & $(32.82 \%)$ \\
\hline West Virginia & West Virginia & Alabama \\
$(27.65 \%)$ & $(31.12 \%)$ & $(32.31 \%)$ \\
\hline Tennessee & Tennessee & West Virginia \\
$(26.11 \%)$ & $(30.97 \%)$ & $(32.29 \%)$ \\
\hline Louisiana & Oklahoma & Tennessee \\
$(25.88 \%)$ & $(29.87 \%)$ & $(32.27 \%)$ \\
\hline
\end{tabular}

Source: Robert Wood Johnson Foundation (RWJF) Data Hub (http://www.rwjf.org/en/researchpublications/research-features/rwjf-datahub.html)

As a second measure of health-related lifestyle, this study utilizes the prevalence of smoking in the adult population at state level based on 2-year averages of the Behavioral Risk Factor Surveillance Survey (BRFSS) data. Smoking prevalence is measured as "the percent of adults who have smoked 100 or more cigarettes in their lifetime and who currently smoke some days or every day" (the Robert Wood Johnson Foundation (RWJF) Data Hub). As with the state level obesity measure, the 2-year averages of the prevalence of smoking in the adult population are fitted over the 2003-2010 sample time period. Table 4 reports the top 5 states in prevalence of smoking among adults in the 2003-2004, 2007-2008, and 2009-2010 time periods, respectively.

Table 4. Top 5 states in prevalence of smoking in adult population

\begin{tabular}{|l|l|l|}
\hline $\mathbf{2 0 0 3 - 2 0 0 4}$ & $\mathbf{2 0 0 7 - 2 0 0 8}$ & $\mathbf{2 0 0 9 - 2 0 1 0}$ \\
\hline Kentucky & West Virginia & West Virginia \\
$(29.14 \%)$ & $(26.70 \%)$ & $(26.19 \%)$ \\
\hline West Virginia & Kentucky & Kentucky \\
$(27.12 \%)$ & $(26.69 \%)$ & $(25.21 \%)$ \\
\hline Tennessee & Oklahoma & Oklahoma \\
$(25.90 \%)$ & $(25.27 \%)$ & $(24.57 \%)$ \\
\hline Missouri & Indiana & Mississippi \\
$(25.64 \%)$ & $(25.08 \%)$ & $(23.14 \%)$ \\
\hline Oklahoma & Missouri & Alabama \\
$(25.61 \%)$ & $(24.73 \%)$ & $(22.22 \%)$ \\
\hline
\end{tabular}

Source: Robert Wood Johnson Foundation (RWJF) Data Hub (http://www.rwjf.org/en/researchpublications/research-features/rwjf-datahub.html) 
In addition to examining lifestyle attributes across the states, this study takes in account variations in the standard of living at state level. For the purpose, we control for real Gross Domestic Product (GDP) per capita released by the U.S. Commerce Department's Bureau of Economic Analysis (BEA) for the 2003-2010 sample time period. It is measured in 2000 dollars and denoted by $g d p p c$.

\section{REGRESSION MODEL}

In order to explain variations in Medicare costs per enrollee at the state level, we define a general representation which is linear in parameters as follows:

$$
y_{i t}=\beta_{1} x_{1 i t}+\beta_{2} x_{2 i t}+\beta_{3} x_{3 i t}+u_{i}+\varepsilon_{i t}
$$

where $\quad y_{i t}=\log (\text { medicost })_{i t}, \quad x_{1 i t}=\log (\text { gdppc })_{i t}, \quad x_{2 i t}=\log (\text { obesity })_{i t}$, $x_{3 i t}=\log (\text { smoking })_{i t}, u_{i}=$ an unobserved individual-specific effect, $\varepsilon_{i t}=$ the idiosyncratic error term, $i=1, \ldots, 51$, and $t=2003, \ldots, 2010$.

Note that two important assumptions are made in the regression model. First, we incorporate nonlinearities into the regression using a log-log model in which all variables are measured in natural logarithm rather than in level. Therefore, each estimated coefficient will be interpreted as the elasticity of the dependent variable with respect to an explanatory variable. Second, a fixedeffects model is fitted under the assumption that the unobserved state-level effect $\left(u_{i}\right)$ is correlated with the explanatory variables $\left(x_{i t}\right)$ but remains constant over time. This assumption is presumed reasonable in that the unit of observation in the sample is indeed a state or the District of Columbia and is sufficiently large to allow for a certain degree of heterogeneity. If the explanatory variables are indeed correlated with the unobserved individual-level effect $\left(u_{i}\right)$, we will obtain consistent and efficient estimates of the coefficients using the specification of a fixedeffects panel data model as follows:

$$
\begin{aligned}
y_{i t}-\bar{y}_{i} & =\beta_{1}\left(x_{1 i t}-\bar{x}_{1 i}\right)+\beta_{2}\left(x_{2 i t}-\bar{x}_{2 i}\right)+\beta_{3}\left(x_{3 i t}-\bar{x}_{3 i}\right)+u_{i}-u_{i}+\varepsilon_{i t}-\bar{\varepsilon}_{i} \\
& =\beta_{1}\left(x_{1 i t}-\bar{x}_{1 i}\right)+\beta_{2}\left(x_{2 i t}-\bar{x}_{2 i}\right)+\beta_{3}\left(x_{3 i t}-\bar{x}_{3 i}\right)+\varepsilon_{i t}-\bar{\varepsilon}_{i}
\end{aligned}
$$

Note that some informational loss will occur with the specification of a fixed-effects model as we lose information on any time-invariant individual-specific characteristics.

However, if the explanatory variables are uncorrelated with the unobserved state-level effect $\left(u_{i}\right)$, the fixed-effects estimator will no longer be efficient. Instead, a random-effects model will be more efficient as follows:

$$
\begin{aligned}
y_{i t} & =\beta_{0}+\beta_{1} x_{1 i t}+\beta_{2} x_{2 i t}+\beta_{3} x_{3 i t}+u_{i}+\varepsilon_{i t} \\
& =\beta_{0}+\beta_{1} x_{1 i t}+\beta_{2} x_{2 i t}+\beta_{3} x_{3 i t}+v_{i t}
\end{aligned}
$$

where $v_{i t}=u_{i}+\varepsilon_{i t}$. Both $u_{i}$ and $\epsilon_{i t}$ in the composite error term $\left(v_{i t}\right)$ are assumed to be meanzero processes and homoscedastic [16].

To determine whether or not the explanatory variables are correlated with the unobserved individual-specific effect, we implement the Hausman test under the null hypothesis $\left(\mathrm{H}_{0}\right)$ as follows:

$\mathrm{H}_{0}$ : The explanatory variables $\left(x_{i t}\right)$ are uncorrelated with the unobserved state-level effect $\left(u_{i}\right)$. 
Health Informatics-An International Journal (HIIJ) Vol.3, No.3, August 2014

The Hausman test statistic is estimated to be chi-square (3) $=0.37$, and the test statistic fails to reject the null hypothesis that the individual-level effect $\left(u_{i}\right)$ is uncorrelated with the explanatory variables, supporting the specification of a random-effects model.

\section{REGRESSION RESULTS}

Because the fixed-effects estimator is still consistent under the null hypothesis, we report the estimation results of both fixed-effects and random-effects models in Table 5. Consider first the estimation results of the random-effects model which was supported by the Hausman test. The estimated Wald chi-square test statistic, chi-square $(3)=3530.88$, rejects the null hypothesis that all the coefficients in the model are zero. Note that the value of the within $R$-squared from the random-effects regression is 0.909 , meaning that more than $90 \%$ of the sample variation in Medicare costs per enrollee is explained by the explanatory variables. The estimated coefficient of the variable $g d p p c$ (real GDP per capita in 2000 dollars) is negative and statistically significant at the 0.01 level. It implies that, given attributes of lifestyle, the average Medicare spending per enrollee at state level declines as the standard of living at state level improves, and vice versa.

As for the attributes of health-related lifestyle, both the estimated coefficients of lifestyle variables, obesity and smoking, are positively associated with the average Medicare costs per enrollee at state level and statistically significant at the 0.01 level. Recall that our empirical specification is a log-log model so that each estimated coefficient is the elasticity of the dependent variable with respect to an explanatory variable. The estimation results imply that a one percent decrease in the prevalence of smoking in the adult population leads to about a 1.58 percent reduction in Medicare costs per enrollee at state level. The estimated impact on Medicare costs per enrollee of the variable obesity is even larger than that of the variable smoking. When the prevalence of obesity in the adult population decreases by a one percent, the average Medicare costs per enrollee at state level fall by more than 2.45 percent. Note that Medicare costs per enrollee at state level are elastic with respect to a change in the variables obesity and smoking, respectively. Because percentage changes in Medicare costs per enrollee are greater than percentage changes in a lifestyle variable, this finding provides policy-makers with important public policy suggestions for advancing health-related lifestyles.

The estimation outcomes of the fixed-effects model are quite consistent with those of the randomeffects model. Although the Hausman test statistic supports the random-effects model over the fixed-effects model, "it often makes sense to think of each [individual-specific effect] as a separate intercept to estimate for each cross-sectional unit" [17, p.498]. It is conceivable to presume that unobserved state-level heterogeneity is present across individual states and the District of Columbia. The $F$-test statistic indicates that all the coefficients in the model are different from zero. All estimated coefficients are statistically significant at the 0.01 level and their signs are consistent with those in the random-effects model, indicating that the estimation results are quite robust to the empirical specifications. The variable $g d p p c$ is negatively associated with the Medicare costs per enrollee at state level, implying that, all else being equal, a state with greater real GDP per capita spends less per Medicare enrollee. The estimated coefficients of the variables obesity and smoking are positive and statistically significant at the 0.01 level. Furthermore, the size of the estimated coefficients of the fixed-effects model are almost the same as those of the random-effects model. 
Health Informatics-An International Journal (HIIJ) Vol.3, No.3, August 2014

Table 5. Results of panel data estimation

\begin{tabular}{|l|l|l|}
\hline $\begin{array}{l}\text { Dependent variable: } \\
\log (\text { medicost })\end{array}$ & Fixed-Effects Model & $\begin{array}{l}\text { Random-Effects } \\
\text { Model }\end{array}$ \\
\hline $\log ($ gdppc $)$ & $-0.1635^{* * * *}$ & $-0.1542^{* * *}$ \\
& $(0.0342)$ & $(0.0308)$ \\
\hline $\log ($ smoking $)$ & $1.6105^{* * *}$ & $1.5757^{* * *}$ \\
& $(0.2766)$ & $(0.2704)$ \\
\hline $\log ($ obesity) & $2.4899^{* * * *}$ & $2.4539^{* * * *}$ \\
& $(0.2796)$ & $(0.2730)$ \\
\hline constant & -2.3443 & -2.2216 \\
& $(1.5921)$ & $(1.5782)$ \\
\hline$R^{2}$ (within) & 0.9087 & 0.9087 \\
\hline$F$-statistic: $\left(\mathrm{H}_{0}:\right.$ all $\left.\beta_{k}=0\right)$ & $F(3,354)=1174.33$ & \\
\hline$F$-statistic: $\left(\mathrm{H}_{0}:\right.$ all $\left.u_{i}=0\right)$ & $F(50,354)=303.27$ & \\
\hline Wald $\chi^{2}$ statistic: $\left(\mathrm{H}_{0}:\right.$ all $\left.\beta_{k}=0\right)$ & & Wald $\chi^{2}(3)=3530.88$ \\
\hline Hausman test & Chi-sq $(3)=0.37$ & \\
\hline
\end{tabular}

***indicates statistical significance at the 0.01 level.

\section{CONCLUSION}

Departing from many prior studies in the literature on Medicare spending which focused on timeinvariant or hereditary demographic characteristics and congenital health status, this study examined state level variations in Medicare costs per enrollee with special emphasis on prominent acquired health-related lifestyle attributes that are more reversible over a short time period. We hypothesize that state level prevalence of reversible health-related lifestyle attributes are highly statistically correlated with state level variations in Medicare costs and we presume that, if our hypothesis is correct, it will enhance our understanding of public health policy strategies for promoting healthier lifestyle. Our main empirical findings are statistically significant and support our hypothesis, especially in that state level variations in Medicare spending is elastic with respect to changes in the prevalence of the two reversible acquired health-related lifestyle attributes - smoking and obesity.

However, this study leaves many important economic and statistical issues unresolved. First, the observations of acquired health-related habits are not confined to specific age groups, nor are they reasonably current. For instance, the prevalence of smoking in the adult population includes not only current smokers but also adults who have smoked 100 or more cigarettes in their lifetime. Second, based on the findings of the current study, there is a need to further investigate a possible endogeneity issue. This study examined state level variations in Medicare spending per enrollee, controlling for health-related lifestyle attributes. However, it is also conceivable that regional difference in Medicare spending, and thus in benefits, could reversely affects health-related lifestyle attributes of the program beneficiaries. 
Health Informatics-An International Journal (HIIJ) Vol.3, No.3, August 2014

\section{REFERENCES}

[1] Stanton, A., (2013, June 30) "Medicare turns 48: A brief history of the program from Truman and LBJ to today", AARP Real Possibilities. Retrieved from http://www.aarp.org/health/medicareinsurance/info-07-2013/medicare-anniversary-july-30-1965.html

[2] Twight, C., (1997) "Medicare's origin: The economics and politics of dependency", Cato Journal, Vol. 16, No. 3, pp309-338.

[3] Palmer, J. \& Saving T., (2006) A Message to the Public. Washington, D.C.: The U.S. Social Security Administration.

[4] Congressional Budget Office, (2008) A CBO Paper: Technological Change and the Growth of Health Care Spending. Washington, DC: Congress of the United States, http://www.cbo.gov/sites/default/files/cbofiles/ftpdocs/89xx/doc8947/01-31-techhealth.pdf

[5] Winfree, P., (2011) Medicare Solvency: How to Get There Backgrounder. Washington, DC: Heritage Foundation.

[6] Gage, B., Moon, M., \& Chi S., (1999) "State-level variation in Medicare spending", Health care Financing Review, Vol. 21, No. 2, pp85-98.

[7] Ashby, J., Fisher, K., Gage, B., Guterman, S., Kelley, D., Lynch, A., \& Pettengill J., (1996) State Variation in the Resource Costs of Treating Aged Medicare Beneficiaries. Washington, DC: Prospective Payment Assessment Commission.

[8] Moon, M., Brennan, N., \& Segal M., (1998) “Options for aiding low income beneficiaries”, Inquiry, Vol. 35, No. 3, pp346-356.

[9] Fisher, E., Wennberg, D., Stukel, T., Gottlieb, D., Lucas, F., \& Pinder E., (2003) "The implications of regional variations in Medicare spending. Part 1: the content, quality, and accessibility of care", Annals of Internal Medicine, Vol. 138, No. 4, pp273-287.

[10] Fisher, E., Wennberg, D., Stukel, T., Gottlieb, D., Lucas, F., \& Pinder E., (2003) "The implications of regional variations in Medicare spending. Part 2: health outcomes and satisfaction with care", Annals of Internal Medicine, Vol. 138, No. 4, pp288-298.

[11] Zuckerman, S., Waidmann, T., Berenson, R., \& Hadley J. (2010) "Clarifying sources of geographic differences in Medicare spending”, New England Journal of Medicine, Vol. 363, No. 1, pp54-62.

[12] Chao, Y. \& Wu C., (2013) "Demand-side factors and Medicare spending growth in the United States", Journal of Global Health Care Systems, Vol. 3, No. 2, pp1-14.

[13] Farrell, D., Jensen, E., Kocher, B., Lovegrove, N., Melhem, F., Mendonca, L., \& Parish B., (2008) Accounting for the Cost of US Health Care: A New Look at Why Americans Spend More. McKinsey Global Institute

[14] Ginsburg, P., (2008) High and Rising Health Care Costs: Demystifying U.S. Health Care Spending Research Synthesis Report. Princeton, NJ: The Robert Wood Johnson Foundation.

[15] Sutherland, J., Fisher, E., \& Skinner J., (2009). "Getting past denial-the high cost of health care in the United States, New England Journal of Medicine, Vol. 361, No. 13, pp1227-1230.

[16] Baum, C. (2006) An Introduction to Modern Econometrics Using Stata, Stata Press.

[17] Wooldridge, J. (2006) Introductory Econometrics: A Modern Approach, 3rd ed., South-Western. 